\title{
Keeping a Prospect on the Line and Then in the Boat: Recruitment and Re- tention Efforts that Make a Difference
}

\section{Dr. Ronald W. Welch, The Citadel}

Ron Welch (P.E.) received his B.S. degree in Engineering Mechanics from the United States Military Academy in 1982. He received his M.S. and Ph.D. degrees in Civil Engineering from the University of Illinois, Champaign-Urbana in 1990 and 1999, respectively. He became the Dean of Engineering at The Citadel on 1 July 2011. Prior to his current position, he was the Department Head of Civil Engineering at The University of Texas at Tyler from Jan 2007 to June 2011 as well as served in the Corps of Engineers for over 24 years including eleven years on the faculty at the United States Military Academy.

\section{Dr. Kevin C. Bower P.E., The Citadel}

Dr. Kevin Bower is the D. Graham Copeland Professor of Civil Engineering and Head of the Department of Civil and Environmental Engineering at The Citadel, Charleston, South Carolina. Dr. Bower's teaching research interests are in improving active learning environments and the development of classroom pedagogy to improve moral development in engineering students.

\section{Dr. Robert J. Rabb P.E., The Citadel}

Robert Rabb is an associate professor and the Mechanical Engineering Program Director at The Citadel. He previously taught mechanical engineering at the United States Military Academy at West Point. He received his B.S. in Mechanical Engineering from the United States Military Academy and his M.S.E. and $\mathrm{PhD}$ in Mechanical Engineering from the University of Texas at Austin. His research and teaching interests are in mechatronics, regenerative power, and multidisciplinary engineering.

\section{Ally Kindel Martin, The Citadel}

Ally Kindel Martin is the Director of Student Success in the School of Engineering. In her position, she has worked with the Supplemental Instruction program, launched STEM Freshmen Outreach initiatives, created an Engineering Mentor Connection program, and revitalized the Engineering Career \& Networking Expo. She holds a M.Ed. in Higher Education and Student Affairs from the University of South Carolina. Previously she worked as a Student Success Adviser and focused on early intervention initiatives. She has taught courses including First Year Seminar, Keys to Student Success and University 101. 


\section{Keeping a Prospect on the Line and Then in the Boat - Recruitment and Retention Efforts that Make a Difference}

The university is experiencing a doubling of engineering enrollments over the last five years after many years of flat enrollments. The school has a unique mission that attracts students from across the nation, so long-term pipeline development is outside the scope of this paper. However, once a student has made contact and then a commitment to attend, there are a number of activities and processes employed both before they arrive and during their first year to maintain the pipeline and retain them in engineering once on campus. The main focus of these efforts are to create a culture of open communications with potential students and increase engagement of engineering students with faculty, engineering professionals, and peers to scaffold resiliency in persisting in engineering degrees.

The overall goal was to design an effective recruiting and retention program that allowed students to be a part of a dynamic and supportive educational environment inside and outside of the classroom. While each first-year student has different needs and challenges, all still need information and resources that will help them succeed as well as connect them to the campus community, so that they feel more fully apart of the learning environment and can meet their educational goals.

This paper will describe and assess the use of college visits, summer school and engineering activities prior to the first year, scholarships, and cohort communities to recruit and retain minorities and females. It also will describe programs and activities during the first year such as supplemental instruction, STEM lab, STEM freshmen events, disciplinary and residence hall tutors that will be shown to have meaningful impact on their persistence and ultimately demonstrate the success of these programs.

\section{Introduction}

The Citadel is primarily a fully residential cohort institution (day program only) that strives to graduate most students in four years. Since The Citadel is a military school, there are unique student requirements that add additional responsibilities and stress to freshmen applying, completing military training prior to academics, and then persisting during the full year, especially in engineering that requires heavier course loads to maintain academic progress. As a result engineering students experience greater demands in their first year than other students.

Most universities are trying to increase enrollments or at least maintain current numbers in the face of the incredibly good economy that leads to fewer students in college. The Citadel, in 2007 as the recession began, understood the need to maintain its student population and worked very hard to be relevant to a larger population of the US. As the State of South Carolina began to climb out of the recession in 2010 (one of the first states to suffer in the recession), The Citadel's President developed a strategic plan that included growth in all areas to include increased retention of students at all academic ranks. Unfortunately, the School of Engineering was experiencing marginal enrollments and reporting poor retention numbers (on average 50-60\% retaining to sophomore year). 
A $360^{\circ}$ assessment of engineering in fall 2011 highlighted the need for increased recruitment and retention efforts. A six-year strategic plan set goals for overall growth of the school to include adding new programs. However, before adding programs and stressing the current system more, recruitment and retention activities were initiated and sustained to build community among the engineering freshmen across all disciplines. These activities increased the confidence of existing engineering programs that current graduation numbers could be maintained through greater overall retention and that the same number of students was not simply going to redistribute over more programs.

Recruitment and retention activities were not done in sequence, but rather new activities were initiated as the program and faculty and staff were prepared to execute them (Table 1). As new activities were brought forward by the team, the team decided on when and how best to execute.

\section{Activities Prior to First Year}

Pre-First Year Visit. In the fall, students can schedule an overnight visit even if they are not accepted, but they must have an application submitted. In the spring, only accepted students can schedule an overnight visit. Students prior to their senior year in high school or students who have not submitted an application can visit The Citadel any day and get an afternoon tour coordinated through Admissions. Initially the only contact prior to arrival with the prospective students was through Admissions, but now the engineering department heads email each student prior to arrival to welcome them and begin to engage them in the community. This contact also opens up an additional line of communication with each applicant and their family as they have questions.

During the overnight visits, the prospective students meet with department representatives. Engineering departments also take the students on a tour of engineering facilities while engaging them in dialogue about activities available to them if they choose to become a part of the learning community (i.e., seeing student projects, recent student chapter awards, etc.). Additionally, they have a number of current freshmen through senior females, minorities, and student athletes present during the tour to engage the students further. After a night in the dormitories, the students traditionally shadowed a freshman student through their morning academic schedule, but the new program allows engineering students to spend an hour with either the dean or a department head discussing what is engineering, how society benefits from engineers, and what career options are available upon graduation. This is followed by two hours participating in engineering courses. Faculty open their classrooms to the student prospects and engage them in the classroom environment. This is a sharp contrast to whatever the freshman host's classes might have traditionally been engaged in (i.e., humanities, leadership, ROTC, physical education, etc.). There is minimal impact to programs to prepare for this activity. Faculty are simply contacted to ensure there will be minimal disruption to their class by having guests observing. The goal of this activity is to have each prospective student see themselves as members of our engineering learning community. Many current students note the actual meetings with the Dean and sitting in engineering classes as critical to their decision. 
Email Contact. The department heads follow-up each visit with an email and make a unique connection with each based on observed question asked or interest. A similar process is followed for the athlete visits. Smaller athletic programs host a single recruit while larger programs like football will bring a single engineer recruiter to three or four larger recruiting events. The recruiter has a meal while visiting and answering questions of the recruits, but more importantly, the family. Engineering has numerous students in each sport on campus to include the club teams of lacrosse and hockey.

$\underline{\text { STEM Scholars Program. }}{ }^{1}$ STEM programs are struggling with having students matriculate from high school, but especially females and minorities. Many institutions provide financial assistance to meet a critical need for underrepresented students in engineering. ${ }^{2}$ The Citadel has initiated a Scholars program to elevate the quality of incoming first year students across multiple programs. The STEM programs made the decision to use these focused scholarships to increase the number of females and minorities (and economically challenged students if there are limited numbers of females and minorities). The goal was to gain access to student early decisions on college through the scholarships. However, the amount was not large enough for this small pool of highly recruited students, so the scholarship packages were increased substantially for year two (current year).

Major Verification. Once students have submitted their deposit, the registrar sends a letter asking each student to verify their initial major. The registrar assigns first year students to their initial first semester courses based on transfer courses and major. This is one more touch point with each family to ensure their son or daughter is initially scheduled for the courses they need prior to arrival. Any student who selects 'Undecided' or selects multiple majors is called by a program representative to determine their interest level in one of the engineering majors and answer any questions. In engineering, either the dean or department heads make the call since this occurs in the summer. Many families are further impressed by this focus on their student by whom calls. It is so important to ensure the 'Undecided' who might be considering engineering starts in the right mathematics and science courses; otherwise, they lengthen their time to graduation which may ultimately lead to a future major change. Since upper level mathematics and science courses needed for engineering also meet mathematics and science requirements for humanities and business, starting in calculus based courses does not impede a change, but greatly assists in timely graduation in STEM majors. Many families express their appreciation for assisting their student to ensure they are in the right mathematics and science courses as they continue to determine their major.

The Citadel Success Institute (CSI). Once a student accepts and submits the deposit in May, the family is reminded that The Citadel has an additional program in the summer to assist their student's transition to (a military) college. The program is called The Citadel Success Institute a four-week summer school program that allows each student to complete four credit hours of college course work and further acclimate to The Citadel by living in the barracks (dormitories) while participating in physical training each morning, marching to class and meals, and following military decorum while still wearing civilian clothes. Engineering has added precalculus as an option allowing more students (nearly double) to start in the fall in Calculus I versus Pre-calculus based on a mathematics placement exam. 
CSI Dean's Brief. - As part of an academic orientation during CSI, the deans of all the schools have an opportunity to discuss their schools' academic programs and events. Here, the students learn about the achievements of the engineering programs, resources available for student success, and opportunities. This is yet another opportunity to either reinforce the student's choice in an engineering major or challenge those who may still be considering an engineering major.

Saturday Mornings during CSI. There are also three Saturdays on campus during the four weeks of summer school and the School of Engineering uses the morning open time slot to conduct engineering hands-on activities (i.e. - construction site tours; water bottle rockets and mini-Baja demo; robotics and sensor development) for all declared engineering majors and anyone who would like to participate. These optional opportunities for non-engineering majors encourage some of these future students to give engineering a try even though they are also excited about a non-engineering major.

Table 1. Recruitment and Retention Activities

\begin{tabular}{|l|l|l|}
\hline \multicolumn{2}{|c|}{ Activities Prior to First Year } \\
\hline Date & Activity & Description \\
\hline Fall-Spring & Pre-First Year Visit & Candidate overnight visit \\
\hline Fall-Spring & Email Contact & $\begin{array}{l}\text { Establish contact prior to } \\
\text { overnight visit, continue } \\
\text { afterwards }\end{array}$ \\
\hline Fall-Spring & STEM Scholars Program & $\begin{array}{l}\text { Focused scholarships to } \\
\text { increase female and minority } \\
\text { STEM majors }\end{array}$ \\
\hline Early Summer & Major Verification & $\begin{array}{l}\text { Contact with 'Undecided' } \\
\text { freshmen to discuss } \\
\text { engineering choices }\end{array}$ \\
\hline July & The Citadel Success Institute (CSI) & $\begin{array}{l}\text { Summer school to allow early } \\
\text { acclimation at military school } \\
\text { with pre-calculus available to } \\
\text { assist in timely graduation of } \\
\text { engineering students }\end{array}$ \\
\hline July & CSI Dean's Brief & $\begin{array}{l}\text { Opportunity to reinforce } \\
\text { those wanting to major in } \\
\text { engineering and challenge } \\
\text { those still considering } \\
\text { engineering }\end{array}$ \\
\hline
\end{tabular}




\begin{tabular}{|c|c|c|}
\hline July & Saturday Mornings During CSI & $\begin{array}{l}\text { Contact with engineering } \\
\text { majors and those interested in } \\
\text { engineering during CSI }\end{array}$ \\
\hline \multicolumn{3}{|c|}{ Activities During First Year } \\
\hline August & Challenge Week & $\begin{array}{l}\text { Academic discipline contact } \\
\text { during military training week } \\
\text { and advising }\end{array}$ \\
\hline August & Convocation and lunch & $\begin{array}{l}\text { Engineering faculty sitting at } \\
\text { each lunch table }\end{array}$ \\
\hline August-December & Freshman Engineering Class & $\begin{array}{l}\text { Advisor is teacher or } \\
\text { connected to the freshman } \\
\text { course at multiple points }\end{array}$ \\
\hline August-September & Mathematics Review & $\begin{array}{l}\text { Prep for current math course } \\
\text { and improved study habits }\end{array}$ \\
\hline Fall-Spring & $\begin{array}{l}\text { Math Lab, Supplemental Instruction } \\
\text { (SI), STEM Lab }\end{array}$ & $\begin{array}{l}\text { Students assisting students in } \\
\text { any first-year or sophomore } \\
\text { course }\end{array}$ \\
\hline Fall-Spring & Director of Student Success & $\begin{array}{l}\text { Select SI and STEM lab } \\
\text { leaders, provide weekly } \\
\text { leader training, develop and } \\
\text { conduct STEM Freshmen } \\
\text { events, counsel struggling } \\
\text { students }\end{array}$ \\
\hline Fall-Spring & STEM Freshman Events & $\begin{array}{l}\text { Monthly events to develop a } \\
\text { first-year community through } \\
\text { fun activities and } \\
\text { motivational speakers }\end{array}$ \\
\hline Fall & Resume Class & $\begin{array}{l}\text { Career Center run resume } \\
\text { building in first year } \\
\text { engineering courses, upload } \\
\text { to HireLink prior to career } \\
\text { fairs }\end{array}$ \\
\hline Fall-Spring & $\begin{array}{l}\text { Mandatory Advising, Add-Drop Form, } \\
\text { Change Major Form }\end{array}$ & $\begin{array}{l}\text { Mandatory advising and } \\
\text { required counseling prior to } \\
\text { signing drop and major } \\
\text { change form to improve } \\
\text { retention }\end{array}$ \\
\hline
\end{tabular}




\begin{tabular}{|l|l|l|}
\hline Spring & Second Semester First Year Course & $\begin{array}{l}\text { Continued weekly } \\
\text { engineering contact while } \\
\text { developing computer skills } \\
\text { for future courses }\end{array}$ \\
\hline Early Spring & E-Week Activities & $\begin{array}{l}\text { Opportunity to compete in } \\
\text { trebuchet and support other } \\
\text { K-12 competitions (i.e. } \\
\text { Trebuchet, craft stick bridge, } \\
\text { robotics, water bottle) }\end{array}$ \\
\hline Fall-Spring & Competition Teams & $\begin{array}{l}\text { Opportunity to support } \\
\text { competitions they could lead } \\
\text { as a junior or senior (i.e., } \\
\text { concrete canoe, steel bridge, } \\
\text { mini-Baja, ethics, robotics) }\end{array}$ \\
\hline Fall-Spring & Club Meetings & $\begin{array}{l}\text { Mentorship, connection to } \\
\text { future internships and jobs, } \\
\text { service opportunities }\end{array}$ \\
\hline Fall-Spring & Special Needs & $\begin{array}{l}\text { Opportunity to compete using } \\
\text { calculus skills only STEM } \\
\text { majors are developing }\end{array}$ \\
\hline January & Instructors & $\begin{array}{l}\text { Providing first year and } \\
\text { sophomore engineering } \\
\text { instructors with learning } \\
\text { style, active learning, course } \\
\text { organization, and } \\
\text { communication skills to } \\
\text { improve quality of student } \\
\text { engagement and learning }\end{array}$ \\
\hline Academic Training for First Year & $\begin{array}{l}\text { Academic training leading to } \\
\text { adjusting content delivery to } \\
\text { teach in each learning style } \\
\text { improves working with } \\
\text { special needs students }\end{array}$ \\
Leadership Symposium & $\begin{array}{l}\text { Present senior capstone, } \\
\text { research, service and } \\
\text { competition projects to } \\
\text { freshmen and sophomores }\end{array}$ \\
\hline
\end{tabular}




\begin{tabular}{|l|l|l|}
\hline May, Fall & Study Abroad & $\begin{array}{l}\text { Engineering focused study } \\
\text { abroad in May for rising } \\
\text { juniors. Fall semester abroad } \\
\text { at engineering focused } \\
\text { universities for rising } \\
\text { sophomores }\end{array}$ \\
\hline Fall-Spring & Sophomore Mentoring Event & $\begin{array}{l}\text { Mentoring each semester to } \\
\text { continue the relationship built } \\
\text { first year during monthly } \\
\text { events }\end{array}$ \\
\hline
\end{tabular}

\section{Activities during First Year}

Challenge Week. The upper three classes return three days prior to classes to move in, reorganize the cadet companies (losses through graduation and gains of incoming freshmen), draw weapons for parades, complete last minute advising and textbook pickup, and complete annual Corps wide training. However, the first-year students report 10 days before classes begin to complete initial military training and acclimate into the culture. "Challenge Week" starts on Saturday with freshmen move-in supported by parents of upperclassmen while the first-year parents participate in a matriculation day fair. There is a table for each organization on campus to include each of the academic schools ending with a presentation by the president and a question and answer session with the parents. At the School of Engineering table, as parents meet with faculty, the parents are given a document with a picture and contact information for all department faculty and the Department Head. A few moments are spent with each parent to identify their student's advisor and, if different, their first-year engineering instructor. Some engineering departments assign the students in the freshman engineering course to the instructor as their advisor. Others ensure the advisor's schedule allows them to visit the first-year engineering class at appropriate times during the semester. With over $95 \%$ of students signing a FERPA waiver before arrival, these simple acts provide the parents much comfort in the ability to contact the advisor who will have class contact with their student at least twice a week their first year.

During "Challenge Week" the first-year students meet three times to focus on academics which are the primary reason most are at The Citadel. The first meeting is with the cadet company academic advisor on Sunday evening. This small break to talk about academics and provide academic resources on a thumb drive provides a much needed break from the rigor of the military training and sets their vision properly on academics starting in nine days. This theme continues throughout the first part of the week to remind the first-year students that academics are coming and the academic semester is very different from "Challenge Week", especially in engineering. The next academic meeting is on Tuesday night with their disciplinary department head. Engineering brings snacks, drinks, and the entire academic team being present to build community. The advisors are able to meet with all their students in a group after the department 
head speaks to allow the first-year students to get to know their advisors before talking schedules. Their next academic meeting is the next morning (Wednesday) where each student meets with their academic advisor to ensure their schedule is correct given any transfer or AP credit. All engineering students waiting on their advising meeting are in an auditorium where there is breakfast food as well as engineering upperclassmen talking about the engineering club and department activities - again building community.

Convocation. The day before classes begin, the first-year students and faculty participate in the Convocation where a faculty member teaching primarily freshmen provides words of wisdom and then all move to the dining hall for lunch (with no upper class students). All engineering faculty participate and spread themselves such that there is usually one engineering faculty member per table of first-year students. This allows any last-minute questions that engineering first-year students have to be answered by engineering faculty - once again building community.

Freshman Engineering Class. In most of the School of Engineering, the faculty member teaching the freshman engineering class is also their advisor. Another option is to split the first-year engineering section between two faculty and ensure they can attend class when discussions focus on careers and academic scheduling. This allows additional conversation leading to fuller discussions during advising. Additionally, when the course requires more faculty support to conduct activities or when mass advising is appropriate or when scheduling face-to-face for advising times, the faculty advisor is available to attend class.

Mathematics Review. ${ }^{3}$ Many first-year engineering students are arriving ill prepared for the rigors of college mathematics. Generally, mathematics professors do not see it as their problem and students need to start at the lowest level and build up their skills missing from high school. If this was done, many would need to start in College Algebra. Instead, most work to improve their skills while trying to survive Calculus or Pre-Calculus. The School of Engineering decided to conduct a mathematics review in the evening during the first ten days of the semester. The faculty teaching the freshman engineering course were the lead instructors - again building community. However, the ability to ensure dedicated evening time, especially ten straight evenings was an impossible task. With some reorganization of the freshman engineering course over a two-year period of time, the entire mathematics review was incorporated while improving the focus of review based on the mathematics level of each student. This focused mathematics review not only elevated mathematics skills, but also improved overall study habits early in the semester that the mathematics professors have noted. The first-year students are told why they are doing the math review that highlights that the engineering faculty are working with them each step of the way.

Math Lab, Supplemental Instruction (SI), STEM Lab. ${ }^{3,4}$ In 2011 a mathematics lab was available two nights a week to provide tutoring, while the writing center was available primarily during the day through appointment or walk-in (if available). It was obvious based on the nearly $50 \% \mathrm{D}, \mathrm{F}$, and W (withdrawal) rate in Mathematics and Chemistry that more was needed (Figure 1). Supplemental instruction was already available for psychology and foreign languages. The School of Engineering began with providing two supplemental instructors in mathematics courses to now having over 30 supplemental instructors providing two hours of tutoring each 
week in the evening for most of the STEM related courses in the freshman and sophomore years. For the courses without supplemental instructors, the School of Engineering established a STEM lab that stations the best supplemental instructors in the evening for two hours Monday through Thursday to assist any first year or sophomore student in a STEM course. The goal is students assisting students and ensuring through unique coverage students can get rapid and early assistance on numerous STEM courses (especially mathematics and chemistry) versus struggling for lengthy periods of time and ultimately falling behind.

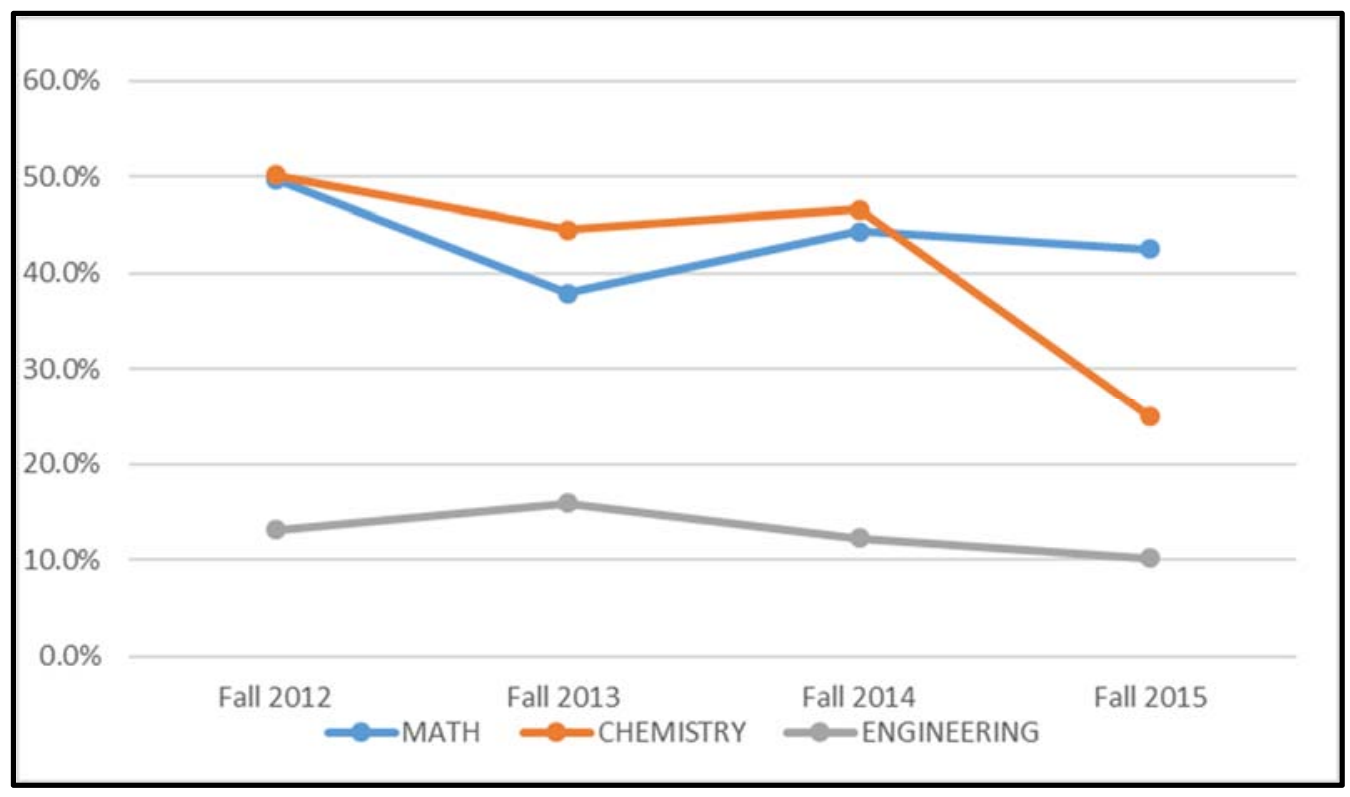

Figure 1. D, F, W rates for Math, Chemistry, and Engineering ${ }^{3}$

Director of Student Success. As the number of programs grew (SI and STEM Lab), the need to select the best students to assume key roles and weekly training was needed. A Director of Student Success in the School of Engineering was established to lead the effort while working with faculty to determine the best students to become supplemental instructors based on observed ability and desire to assist peers. This was only the beginning of programs to assist in building community and assisting the students to succeed in engineering (other activities listed next).

STEM Freshman Events. ${ }^{3}$ Many universities have freshmen engineering courses in the first semester to engage first year engineering students to encourage and motivate them to overcome the difficulties they are experiencing in the other courses, and have fun so they remain in engineering. The Director of Student Success developed STEM Freshman Events hosted once a month to engage the students and further build community among the first-year engineering students. The first event occurs within the first full academic week and the sole purpose is to feed them in a relaxed environment (no upper class) while having fun playing board and card games with students in other STEM disciplines. We average about $85 \%$ of the first year STEM students with the rest attending fall athletic practice. The next two have a speaker followed by speed mentoring by a number of STEM professionals tied to the company making the presentation. The attendance is on average $80 \%$ of the first-year engineering students. The last 
fall event is a ginger bread building contest focused on teamwork and creativity. This event usually draws $93 \%$ of the first-year engineering students. The spring events all focus on guest speakers with speed mentoring with nearly $75 \%$ attendance. The high attendance and student comments as they progress throughout the year support the importance of these events on building community and ultimately assisting in retention.

Resume Class. Each first-year engineering course hosts a resume building class by the career center to encourage early development of a good resume. These resumes are then placed on HireLink to allow companies attending any of the career fairs to access them. Through the early development of resumes and the addition of bonus points in the freshmen engineering course for attending the Engineering Career and Networking Expo, the Director of Student Success works with engineering faculty to encourage all first-year engineering students to attend and earn opportunities for internships. The first-year early experience of a career fair demonstrates the need for the skills they will be developing, further encouraging them to fight through the early difficulties many engineers experience in college to eventually attain the degree.

Mandatory Advising, Add-Drop Form, Change Major Form. The Citadel is a small university. This fact is good and bad. The good is most of the faculty know most of the students. The bad is that courses are only offered once a year. When there was no mandatory advising, a number of students would not schedule a pre-requisite course that would result in a year setback. The inclusion of academic holds for all engineering students, especially true for engineering first year students, ensures students are advised on the correct sequencing of courses to meet pre-requisites and timely graduation. The requirement for all drop forms to be signed by the discipline advisor (engineering requires department head) ensures that the engineering student, especially first year students, understand the long-term effects (timely graduation) of dropping any course, but specially any that are pre-requisites for the next semester courses. This is also true for the Change Major Form that also requires the Department Head signature. This allows the department head to provide a larger vision for working through academic difficulties as well as collect critical data as to why students are leaving engineering. If a pattern emerges, the School of Engineering can expend resources to possibly correct an issue. The issue that was highlighted through this process was high $\mathrm{D}, \mathrm{F}$, and $\mathrm{W}$ (Withdrawal) rates in mathematics and chemistry that became the primary driver for growing SI and STEM Labs above.

Second Semester First Year Course. ${ }^{5}$ Each engineering program developed the appropriate second semester first-year course to ensure engineering students are continually engaged and informed by engineering. Without an engaging second semester course, first-year students will only take mathematics, science, and humanities and social science courses that are not focused on retaining engineering students. As many first-year students continue to struggle for another semester before locating their rhythm, the ability to be engaged in engineering activities and events through classroom announcements keeps many focused on the prize at the end.

E-Week Activities. Something motivated current first-year students to seek an engineering degree. Many times, it was engineering related K-12 STEM activities that caught their attention. The Citadel encourages most first-year students to engage (mentor, run, judge, set-up, etc.) in one of the many engineering activities (1000 participants and 4000 visitors) during E-Week: 
craft stick bridges, robotics, water bottle, and trebuchet competitions. Some participate (college entries), but many come full circle to help coordinate the event for K-16 participants where these students might become motivated to be engineering students themselves. Since The Citadel is a military school, the ability for K-12 students to interact with first year as well as upper class students allows prospective engineering students, especially those desiring to attend The Citadel, a clearer picture of what the future could be. Local students are specifically recruited to link up with students from their school who are competing. The Citadel also coordinates and executes a Women in Engineering event each year for the local girl scout troops. This event allows our female engineers to focus specifically on increasing the number of young women interested in STEM careers. It also allows them to volunteer alongside female engineers from companies such as Bosch, Boeing, Volvo, Mercedes Benz Trucks, Continental Tire, and county and city engineers. A local consortium conducts a STEM Festival (10,000 visitors) where The Citadel School of Engineering has tables for each discipline. Each department operates the table with first year students, a couple of upperclassmen to lead, and a faculty member. The first-year students particularly enjoy working primarily with K-6 students who remind many of siblings at home.

Competition Teams. Engaging freshmen in team based projects and competitions has been shown to the increase student retention and success. ${ }^{6}$ Each engineering department has annual competitions they enter (concrete canoe, steel bridge, mini-Baja, ethics, robotics). It is clearly important for team development over time to include as many first-year students as possible. However, first year student involvement displays directly for them the engineering leadership opportunities that they will have as they remain and grow within the engineering programs.

Club Meetings. ${ }^{2}$ Each department conducts monthly discipline specific club meetings (ASCE, ASME, IEEE) with a guest speaker or activity. These events usually have heavy first year participation since there is pizza and dessert provided normally by the speaker's company. These opportunities to engage with local companies who have internship and full-time employment opportunities provide unique mentoring and encouragement to retain in engineering. The School of Engineering also supports non-discipline specific engineering club meetings (SAME, SWE, NSBE) to provide unique mentoring opportunities for female and minorities as well as mentoring from companies that generally hire engineers from numerous engineering disciplines (Boeing, Mercedes Benz Trucks, Volvo, etc.).

Mathematics Jeopardy. The Mathematics Department hosts an annual Mathematics Jeopardy Bowl each fall. The faculty in the first-year engineering courses work to have their students develop teams to compete and use the unique skills they are developing to carry the engineering banner forward. Most years the top five positons are $85 \%$ filled by engineering majors.

Academic Training for First Year Instructors. Senior faculty at The Citadel have been involved with the ASCE ExCEEd Teaching Workshop for a number of years. As part of the transformation to focus on retention of students, the quality of the student engagement and learning needs to make students want to go to class. The pedagogy and techniques taught as part of the workshop have been known to lead to teaching awards for many of the faculty who attend, but most, if not all experience higher student end-of-course evaluations outpacing most of their 
peers in their departments. The Citadel conducts its own mini-ExCEEd teaching workshop every other year to ensure all new faculty (17 to date, which is over half of the current faculty) have attended. These faculty are also the primary faculty teaching the first-year and many of the sophomore courses each year versus the most senior faculty 6 years ago. The improved teaching quality and training on developing rapport with students has an impact on improved retention from first-year to sophomore year.

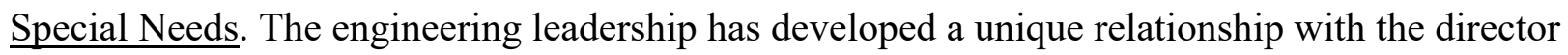
of students with special needs. The faculty attending the mini-ExCEEd teaching workshop receive pedagogical training to vary their teaching to meet the learning styles of students (active vs. reflective, sequential vs. global, sensory vs. intuitive, verbal vs. visual). When faculty ensure each lesson allows a student to learn some content in a preferred style, it assists each student's level of understanding. Forcing each student to learn in their less preferred learning style also encourages each student to develop their least preferred learning style. This training and adjustment to class content delivery allows faculty to more fully understand the learning deficiency that the special needs exception supports (twice as much time on exams, note taker, etc.). This understanding also allows the director to work more closely with engineering faculty working with first year students to develop the best support possible allowing these students to be successful in one of the most demanding majors.

Leadership Symposium. The annual leadership symposium has evolved over the last five years to include each academic school running a panel session on the Thursday afternoon of the event, and to highlight on Friday morning senior capstone, research, service and competition projects. Engineering petitioned and was allowed to ensure first-year and sophomore students can sign up for engineering projects first to use the projects for retention efforts by highlighting the types of senior projects students can be involved with. Some of the projects allow sophomore and junior students to be engaged as well.

Study Abroad. The School of Engineering conducts an engineering only study abroad opportunity for 3 weeks each May for rising junior students. This opportunity is advertised heavily in the freshmen courses to motivate students to retain in engineering and to strive for excellence to participate. The Citadel works hard to have students desiring a semester abroad experience to participate fall of sophomore year. This program is heavily advertised in first year courses and the locations best for engineering students is highlighted by the faculty. The Citadel has quickly doubled its number of students participating to $15 \%$.

Sophomore Mentoring Event. The mentoring process mentioned above in STEM Freshmen Events is such a huge success and an explicit need for the students that they have requested an event once a semester during their sophomore year (need to be connected). This opportunity only available for engineering students is also advertised during the first year courses. It is also during these sophomore events that students are recruited for SI.

\section{Recruitment and Retention Results}

The goal was to grow engineering to provide additional engineering graduates for the Lowcountry, the state, and the nation. The first step was to improve our retention of the young 
people arriving to begin the journey to become engineers. This step was critical to demonstrate to the administration that engineering was worthy of additional resources being used to grow engineering at The Citadel. Table 2 and 3 presents the undergraduate student enrollment for each of the engineering programs over a number of years. The initial growth in the evening programs in 2010 was a direct result of the growth of the aerospace industry in the area. With more technicians in the area, more wanted to improve their skills in electrical engineering (did not have mechanical engineering until 2014). As can be seen from 2010-2014, the School of Engineering experienced higher retention efforts prior to adding the mechanical engineering program in 2014. Mechanical Engineering's first graduating class was three, the second was 17, and this coming year it will be 54 .

Table 2. Undergraduate Enrollments by Year for Each Engineering Program (Day)

\begin{tabular}{lccccccc}
\hline Degree Type & Fall 2011 & Fall 2012 & Fall 2013 & Fall 2014 & Fall 2015 & Fall 2016 & Fall 2017 \\
\hline Civil Engineering & 212 & 239 & 255 & 256 & 230 & 223 & 201 \\
\hline Electrical Engineering & 144 & 166 & 166 & 141 & 125 & 107 & 97 \\
\hline Mechanical Engineering & & & & & & & \\
\end{tabular}

Table 3. Undergraduate Enrollments by Year for Each Engineering Program (Evening)

\begin{tabular}{lccccccc}
\hline Degree Type & Fall 2011 & Fall 2012 & Fall 2013 & Fall 2014 & Fall 2015 & Fall 2016 & Fall 2017 \\
\hline Civil Engineering & 26 & 31 & 32 & 32 & 26 & 29 & 32 \\
\hline Electrical Engineering & 27 & 36 & 46 & 43 & 48 & 48 & 41 \\
\hline Mechanical Engineering & & & & 3 & 14 & 18 & 26 \\
\hline
\end{tabular}

The School of Engineering is constantly reviewing its growth over a five-year period to be able to request additional resources as needed. Table 4 demonstrates the continued growth of undergraduate engineering enrollments over the last 5 years. Since we sold future growth on retention efforts, the natural question is whether growth due to the new Mechanical Engineering program could be masking actual retention. 
Table 4. Undergraduate Engineering Enrollments by Student Classification

\begin{tabular}{|l|c|c|c|c|c|c|}
\hline Student Type & Fall 2012 & Fall 2013 & Fall 2014 & Fall 2015 & Fall 2016 & Fall 2017 * \\
\hline Active Duty Students & 19 & 14 & 10 & 13 & 9 & $\mathbf{8}$ \\
\hline Evening Undergraduate Students & 65 & 66 & 64 & 127 & 95 & $\mathbf{9 9}$ \\
\hline Fifth Year Students & 12 & 16 & 22 & 21 & 26 & $\mathbf{1 7}$ \\
\hline Cadets & 356 & 370 & 423 & 412 & 497 & $\mathbf{5 3 5}$ \\
\hline Veteran Students & 20 & 42 & 43 & 37 & 33 & $\mathbf{3 0}$ \\
\hline Total & $\mathbf{4 7 2}$ & $\mathbf{5 3 6}$ & $\mathbf{5 6 2}$ & $\mathbf{6 1 0}$ & $\mathbf{6 6 0}$ & $\mathbf{6 9 1}$ \\
\hline
\end{tabular}

* Fall 2017 Enrollment data as reported to CHE

Table 5 provides tracking of engineering enrollments from the day they arrive for "Challenge Week" until add/drop (number in parentheses) ends after the first full week of classes. Prior to adding retention methods in 2012 , the retention was barely $44 \%$ retention to the sophomore year. Initial retention efforts (SI) quickly moved the needle to above $50 \%$ retention of entering freshmen to sophomore year. As more retention programs began and matured, the retention from freshman to sophomore year has steadily improved (Table 5).

The program has no control over departures: 1) during the three days after Challenge Week ends and before classes begin (not wanting to be in a military environment for school); 2) the changing of major to a less demanding one (engineering has at least 10 extra credit hours and higher mathematics and science requirements); 3 ) in the first week (many students have interest in multiple majors). Therefore, the School of Engineering began tracking student numbers as of Add/Drop. The goal by fall of 2018 was $72-75 \%$ retention. As noted, the School is exceeding that goal for the last two years. The goal by 2024 is $82-84 \%$ retention. Again, this number might seem low to some, but the strong desire to graduate in four years with the starting cohort (military culture), the daily stress of the military, physical environment and fourth class system freshman year, and the fact we accept all into the program (average SAT 1100) as they enter (no pre-engineering program) make this a very good number. In fact, as we track engineering students that start sophomore courses similar to courses that must be passed for students to move from pre-engineering programs into being full-fledged engineering majors, we graduate $82.5 \%$ in four years and $92 \%$ in six years. These numbers are comparable to the best programs in the country. 
Table 5. Engineering Retention from Freshmen to Sophomore Year

\begin{tabular}{|lccc|}
\hline & Fall & Fall & $\%$ Retained \\
& Freshmen Yr. & Sophomore Yr. & \\
Class of 2014 & 116 & 63 & $54 \%$ \\
Class of 2015 & 118 & 79 & $67 \%$ \\
Class of 2016 & 162 & 101 & $62 \%$ \\
Class of 2017 & 159 & 99 & $62 \%$ \\
Class of 2018 & $175(158)$ & 116 & $66(73 \%)$ \\
Class of 2019 & $193(166)$ & 128 & $66(77 \%)$ \\
Class of 2020 & $203(183)$ & 149 & $73(81 \%)$ \\
Class of 2021* & $186(182)$ & & \\
\hline
\end{tabular}

*Class of 2021 is preliminary data for Fall sophomore year and percent retained is data based on Spring 2018 course enrollments. As of December 2017, there are 20 change of majors out of 182 , new total $162-89 \%$ return.

Note: (\#) represents the total after losing students during challenge week and before Add/Drop

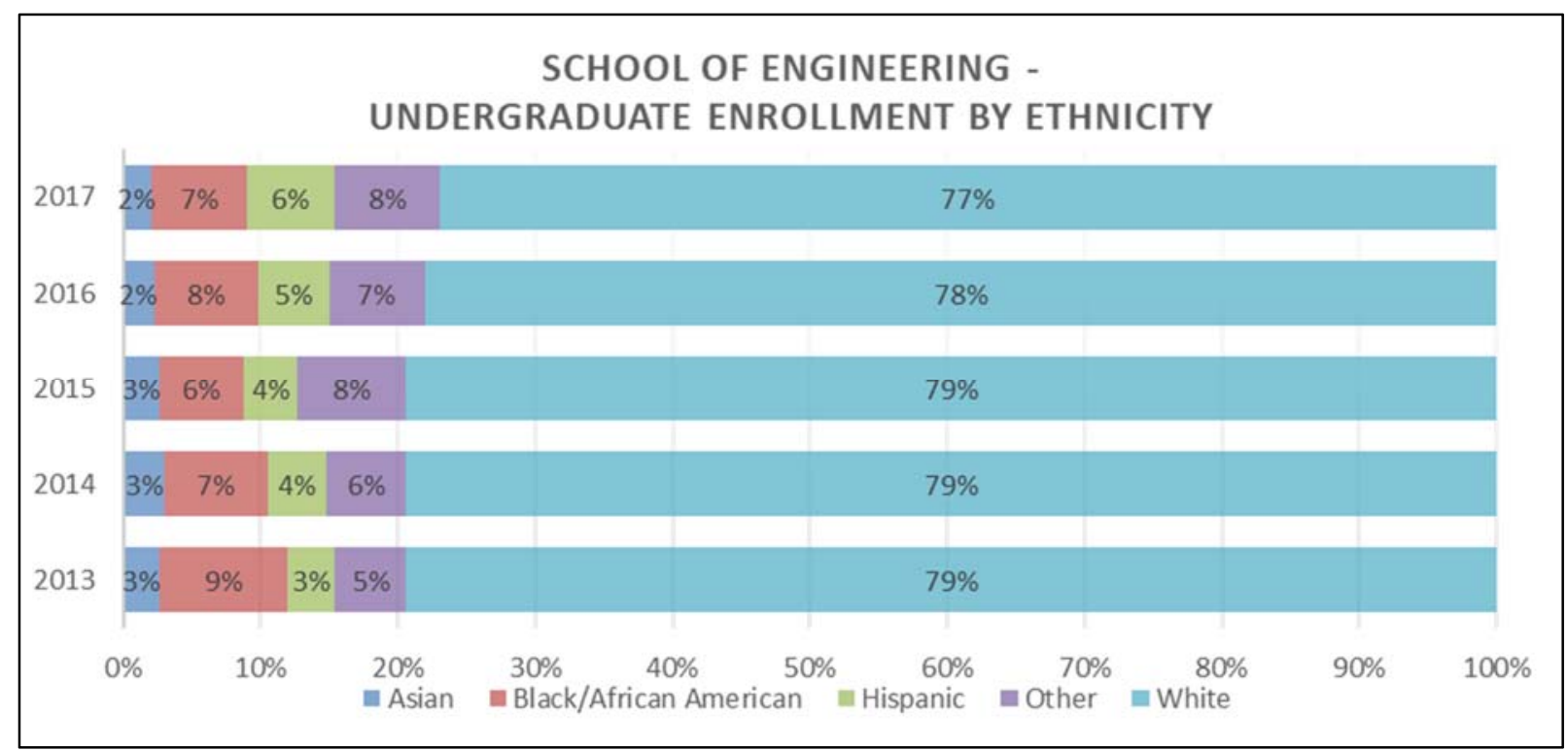

Figure 2. Undergraduate Enrollment by Ethnicity 
These retention and recruitment efforts have had a dramatic impact on our minority and female numbers in engineering as well. In 2011, we had $82 \%$ white students and 6 female students $(2 \%)$. As we look back over the last five years, we see (Figure 2 and 3 ) growth in both areas: $77 \%$ white students while nearly doubling the student population overall and now 31 female students $(4.7 \%)$. These two areas are continued priorities as is retention over the next 6 years.

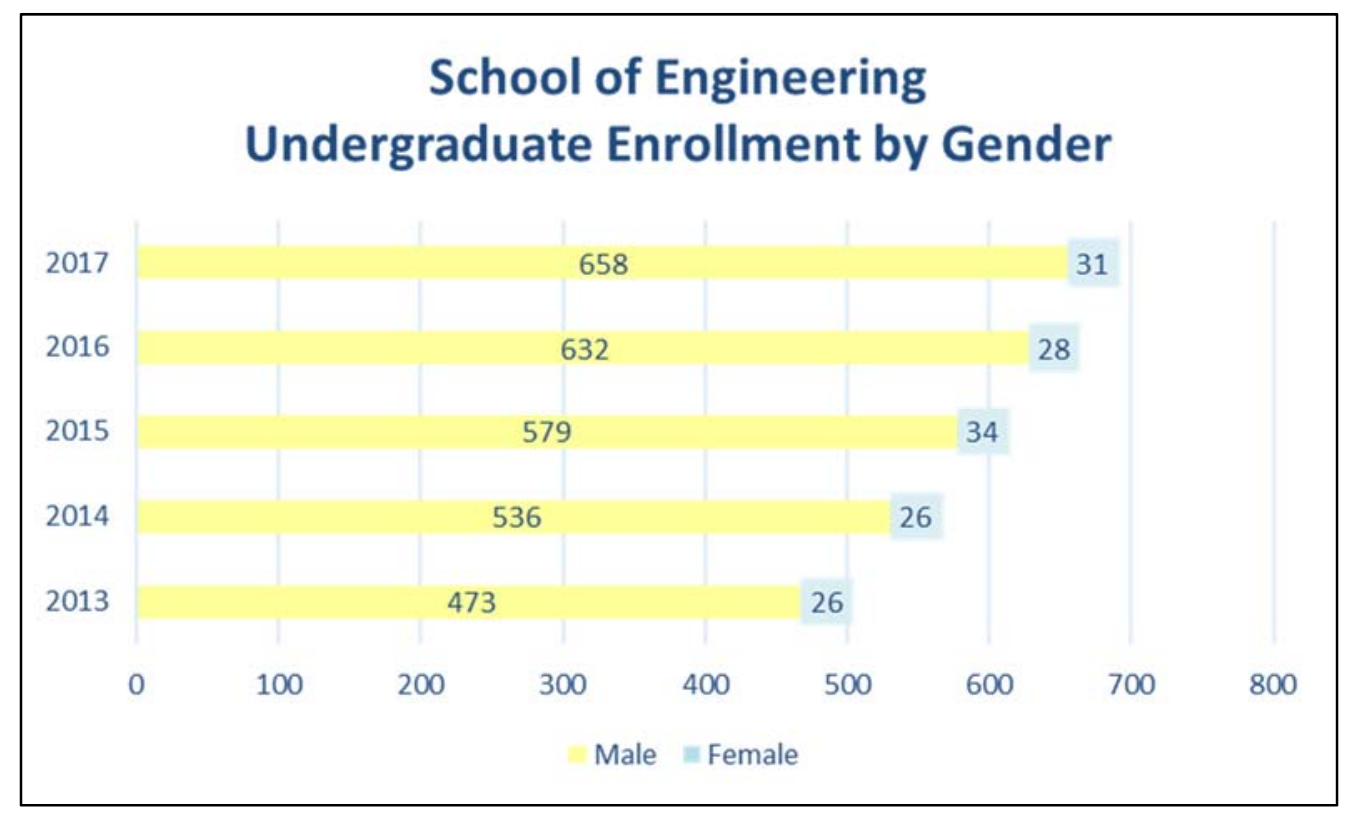

Figure 3. Undergraduate Enrollment by Gender

Many programs hoping to improve their female and minority student numbers increase the number of female and minority faculty. The Citadel started with retention programs as well as started SWE and NSBE student chapters before adding diverse faculty. By highlighting the programs to increase student diversity, recruitment and eventual hiring of a more diverse faculty was possible. In 2011, there were two Asian faculty. In 2017, there were three Asian, four female, two black male faculty, one native American - all hired since 2013.

\section{Conclusions}

In 2011, The School of Engineering took the challenge to increase enrollments while also retaining more who arrive to major in engineering. First action was retention efforts that showed immediate potential (SI). With the addition of new programs and continued improvement in retention percentages, the School of Engineering has developed a number of best practices to share with others (Table 1). Although it is true that data does not exist on one activity overall that was the most impactful, many of these programs were assessed in Civil Engineering. ${ }^{7}$ Similar results have been seen in all of our programs. The key was to start with supplemental instruction which led to a school-wide effort that students are key to assisting others to be successful. Additionally, the development of community within each cohort greatly enhances the desire to stay a part of an overall unique, hardworking, and highly talented engineering team. The improvements in retention for cohorts with an average SAT of 1100 can only be possible when the students take advantage of the resources available and work hard to improve their GPA each 
semester. The Citadel School of Engineering believes that adding the programs in Table 1 and the change in attitude of the faculty to encourage students to seek out assistance as well as use and be a part of many engineering resources and activities in Table 1 is key to the overall success.

Doubling enrollments, moving retention from a low of $40 \%$ to a high of $81 \%$, increasing by five times the female engineering students, and improving diversity by $5 \%$ in six years is notable, no matter where the program in located in the US. Others can see similar results by considering implementing the programs listed in Table 1.

\section{References}

1. Welch, R.W., Bower, K.C., Rabb, R.J., Martin, A.K., Barsanti, R.J. Jr., STEM Scholarships to Engage Exceptional Students, ASEE Annual Conference 2017, Columbus OH, 2017.

2. American Society for Engineering Education (ASEE), "Going the distance: Best Practices and Strategies for Retaining Engineering, Engineering Technology and Computing Students," Washington, DC, 2012. http://www.asee.org/retention-project.

3. Welch, R.W., Martin, A.K., Bower, K.C., Rabb, R.J., Promoting Engagement through Innovative and Pragmatic Programs, ASEE Annual Conference 2016, New Orleans, LA, 2016.

4. Welch, R.W., Martin, A.K., Marley, K., Using Supplemental Instruction to Increase Retention in Engineering, ASEE Annual Conference 2014, Indianapolis, IN, 2014.

5. Rabb, R.J., Bubacz, M.B., Howison, J.H., Skenes, K.L., Design and Assessment of a New First Year Freshman Mechanical Engineering Sequence, FYEE Annual Conference 2015, Roanoke, VA, 2015.

6. Bodnar, L., et.al., "Engaging Freshman in Team Based Engineering Projects," ASEE Annual Conference 2012, San Antonio, TX, 2012.

7. Welch, R.W. Watson, M.K., Martin, A.K., "Examining the Impacts of Academic and Community Enrichment Resources on First-Year Civil Engineering Students," ASEE Annual Conference 2018, Salt lake City, UT, 2018. 